\title{
Two Cases of Endobronchial Neurilemmoma and Review of the Literature in Japan
}

\author{
Kei KaSAhara, Kazuya FuKuOKA, Mitsuru Konishi, Kaoru HamadA, \\ Koichi MAEDA*, Keiichi MIKASA and Hiroshi KIMURA
}

\begin{abstract}
Neurilemmomas are benign tumors which originate from Schwann cells. They rarely occur in the trachea or bronchus. We encountered two cases of endobronchial neurilemmoma and in this context, reviewed 48 cases previously reported in Japan. Neurilemmomas can occur in all regions of the bronchial tree and they often progress into both intraluminal and extraluminal spaces. Incomplete resection results in a local recurrence, despite being rare. As for appropriate therapies, surgery, bronchofiberoptic removal and yttrium aluminum garnet (YAG) laser resection can be chosen depending on the patient's status.
\end{abstract}

(Internal Medicine 42: 1215-1218, 2003)

Key words: neurilemmoma, bronchoscopy, endobronchial tumor

\section{Introduction}

Neurilemmomas are benign tumors which originate from Schwann cells. It is conceivable that neurilemmomas rarely occur in the trachea or bronchus, even though the exact frequency is unknown (1). For the treatment of tracheal or endobronchial neurilemmomas as a palliative therapy, removal by fiberoptic bronchoscopy forceps or intrabronchial resection with a laser has recently been reported to be useful (2), but local recurrence is also reported due to inadequate eradication (2-4). We encountered two cases of endobronchial neurilemmoma, and reviewed 48 cases of pulmonary neurilemmoma in Japan in order to clarify the characteristics of this disease and selection of the appropriate treatment.

\section{Case Report}

\section{Case 1}

A 76-year-old man was under observation after he had received a right upper lobectomy of a squamous cell carcinoma of the lung $\left(\mathrm{T}_{2} \mathrm{~N}_{2} \mathrm{M}_{0}\right.$, stage $\left.\mathrm{III}_{\mathrm{A}}\right)$ in 1998. In 1999, because of a recurrence of lung cancer being suspected in the chest CT, he was admitted to our hospital. On admission, he had no symptoms and his physical examination was essentially unremarkable. We performed a bronchofiberscopy and confirmed the histologic evidence of recurrence of lung cancer in the right upper bronchus and, by chance at the same time we detected a small polyp-like lesion in the spur of the middle and lower bronchus. A bronchofiberscopic biopsy was conducted and the subsequent HE stain (Fig. 1) revealed that the lesion consisted of spindle cells proliferated with Antoni A formation. The $\mathrm{S} 100$ immunoperoxidase stain was positive (Fig. 2) while the alpha-smooth muscle actin ( $\alpha$-SMA) stain was negative, leading to our diagnosis that the lesion was a neurilemmoma. He was still asymptomatic and the small lesion ( 2 to $3 \mathrm{~mm}$ of diameter) permitted us to remove it by a transbronchial biopsy alone. He died one year later due to the recurrence of the cancer.

\section{Case 2}

An 86-year-old man underwent an operation for gastric cancer. After the operation, he developed pneumonia and was intubated. Bronchofiberscopy was performed in order to remove bronchial mucus by suction and we detected a small polyp-like lesion ( 2 to $3 \mathrm{~mm}$ of diameter) in the left B5 a/b by chance. The small lesion was located apart from the pneumonia. The histological finding of the small polyp-like lesion was indicative of neurilemmoma. The small lesion allowed us to remove it by biopsy alone. The patient died a few weeks later due to the pneumonia.

From the Second Department of Internal Medicine and *the Department of General Medicine and Clinical Investigation, Nara Medical University, Nara Received for publication March 27, 2003; Accepted for publication August 7, 2003

Reprint requests should be addressed to Dr. Kei Kasahara, the Second Department of Internal Medicine, Nara Medical University, 840 Shijo-cho, Kashihara, Nara 634-8522 


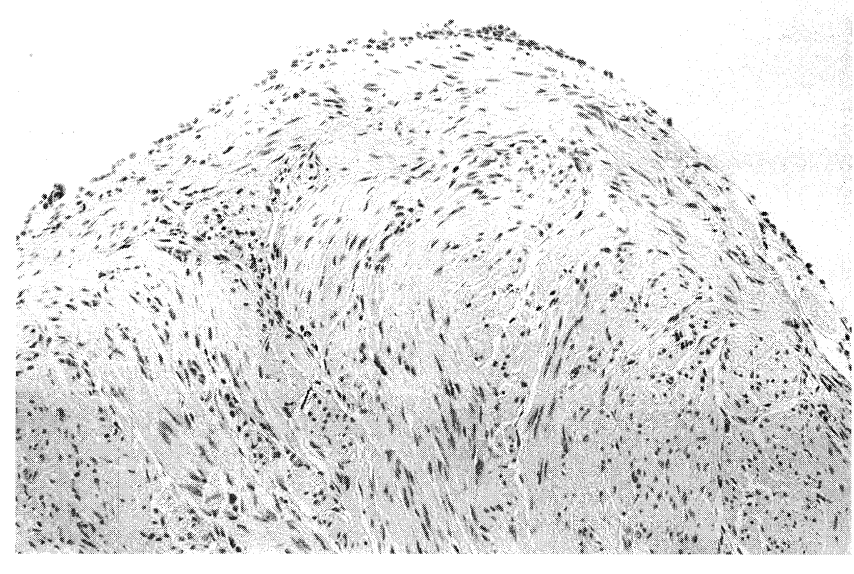

Figure 1. Spindle cells forming Antoni A formation (HE stain, $\times 100$ ).

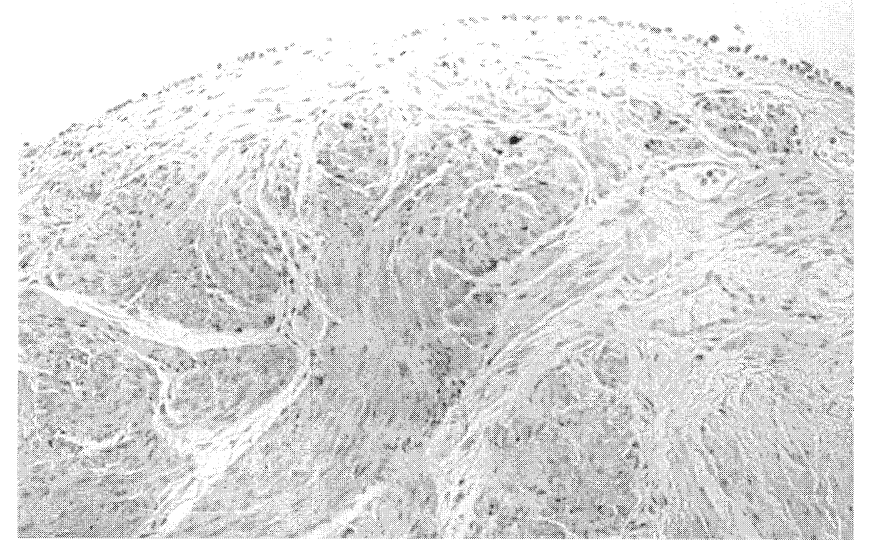

Figure 2. Spindle cells in the neurilemmoma showing a positive reaction with anti-S100 antibody (S100 immunoperoxidase stain, $\times 200$ ).

\section{Discussion}

Although being very rare, pulmonary neurilemmomas can occur in all respiratory tracts including the trachea, bronchus, bronchioles and alveoli. Our review of 50 cases (5-20) (including the present two cases) reported to date in Japan disclosed that pulmonary neurilemmomas can be divided into two major types such as central type and peripheral type (Table 1). When the lesion is located in the trachea or in the proximal bronchus and is visible by bronchofiberscopy, the lesion can be classified as the central type. Such lesions can cause symptoms such as cough and wheezing due to stenotic airways. This type of disease can grow into both intraluminal and extraluminal spaces; however, the extraluminal progression can lead to a recurrence after endoscopic resection of intraluminal lesions. Given all this, we propose classification of the central type into the following two subtypes: 1) lesions which exist only in the intraluminal space and 2) lesions which occur in both intraluminal and extraluminal spaces (combined type). The peripheral type includes lesions which cannot be detected by bronchofiberscopy but can be detected by chest X-ray or CT as a nodule. These lesions are usually asymptomatic. Demographics of the reviewed cases are summarized in Table 2. There seems to be no gender differences in the prevalence of the disease. Diagnosis of pulmonary neurilemmomas is made based on the typical Antoni A formation in HE stain and positive S100 immunoperoxidase stain. As one of the concerns, it could be pointed out that the biopsy specimen amount was not sufficient in most of the cases to accomplish a definite diagnosis of the disease, together with inadequate frequency of the diagnosis by bronchofiberoptic biopsy even in the central type. In view of treatment, the combined type makes the situation complicated as described below. Thirty-seven cases had lesions detectable by bronchofiberscopy and out of them, 26 cases underwent surgery. Among these 26 cases, 12 cases were considered as having only intraluminal lesions before surgery; however, postoperatively they were found to have extraluminal lesions. Nine cases in the tracheal and bronchial type were under observation or underwent resection by

Table 1. Classification of Pulmonary Neurilemmoma according to Its Site and Extension

\begin{tabular}{|c|c|c|c|}
\hline \multirow[b]{2}{*}{ Type } & \multicolumn{2}{|c|}{ Central type } & \multirow[b]{2}{*}{ Peripheral type } \\
\hline & Intraluminal & $\begin{array}{l}\text { Both Intra- and Extraluminal } \\
\text { (combined type) }\end{array}$ & \\
\hline Site & Trachea or proximal bronchus & Trachea or proximal bronchus & Distal bronchus \\
\hline Extension & Only in intraluminal space & $\begin{array}{l}\text { Both in intraluminal and extra- } \\
\text { luminal space }\end{array}$ & $\begin{array}{l}\text { Both in intraluminal and extra- } \\
\text { luminal space }\end{array}$ \\
\hline Detection & $\begin{array}{l}\mathrm{BFS} *^{* 1} \text { and sometimes by chest } \mathrm{X} \text { - } \\
\text { ray or CT }\end{array}$ & $\begin{array}{l}\text { Both by BFS and chest X-ray or } \\
\text { CT }\end{array}$ & Only by chest X-ray or CT \\
\hline Symptom & Cough, wheeze & Similar to intraluminal type & Nothing \\
\hline Therapy & BFS resection by forceps or laser & Surgical operation & Surgical operation \\
\hline
\end{tabular}

$*^{1}$ BFS: Bronchofiberscopy. 
Two Cases of Endobronchial Neurilemmoma

Table 2. Summary of Cases of Pulmonary Neurilemmoma Reported in Japan

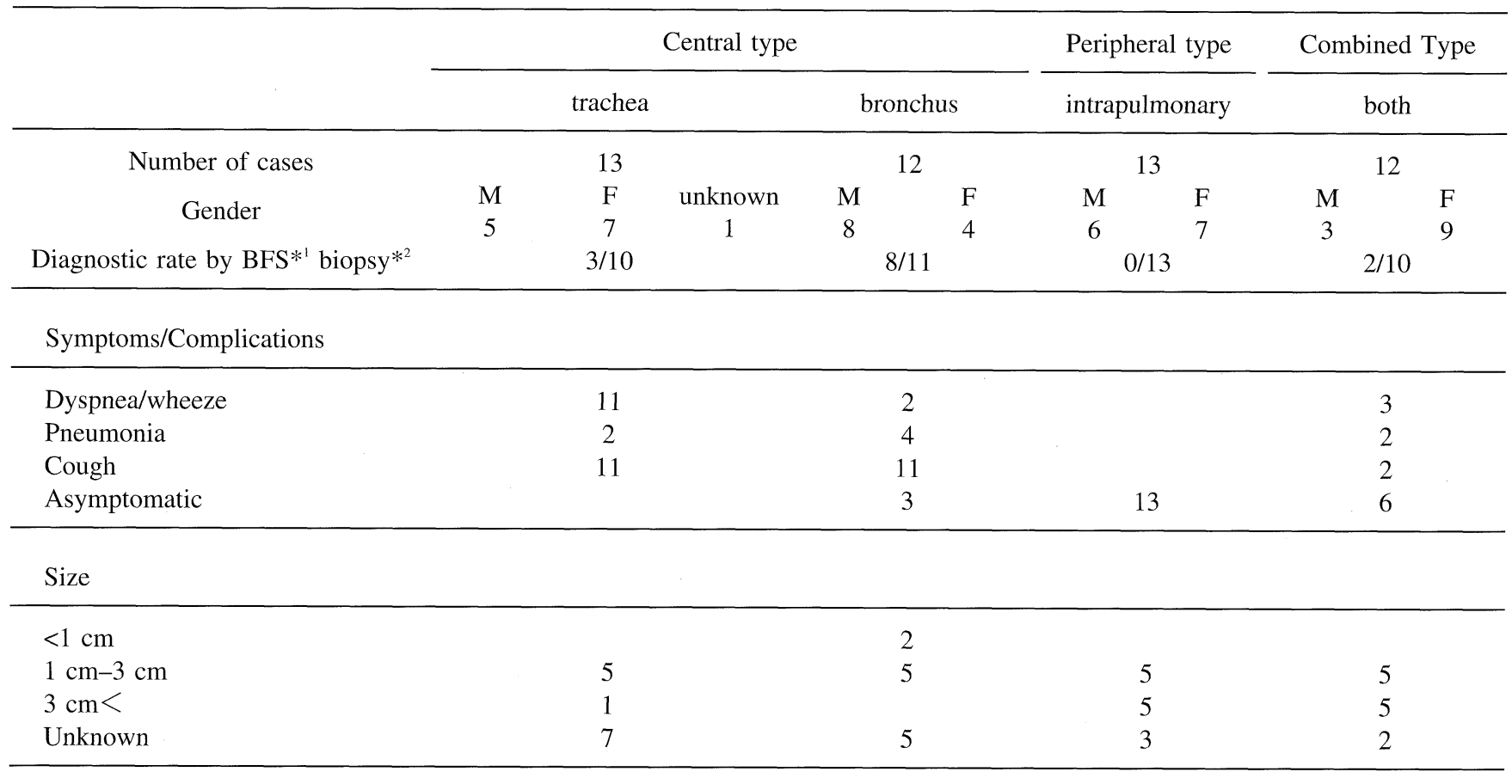

From onset of symptoms to diagnosis

\begin{tabular}{|c|c|c|c|c|}
\hline$>1$ month & 1 & 1 & & \\
\hline 1 to 6 months & & 3 & & 1 \\
\hline$>6$ months & 7 & 2 & & 2 \\
\hline by chance & 1 & 1 & 6 & 8 \\
\hline Unknown & 4 & 5 & 7 & 1 \\
\hline \multicolumn{5}{|l|}{ Treatment } \\
\hline Endoscopic & 1 & 6 & & \\
\hline Operation & 11 & 4 & 13 & 12 \\
\hline YAG laser & 1 & & & \\
\hline Observation & & 2 & & \\
\hline
\end{tabular}

${ }^{*} \mathrm{BFS}$ : Bronchofiberscopy. *2calculated by "number of accurate diagnosis (neurilemmoma)/number of BFS done".

fiberoptic bronchoscopy forceps, whereby most of them showed no evidence of local recurrence during a follow-up period from 2 weeks to 3 years. These findings suggest that about half of the cases of intraluminal neurilemmomas have non-apparent extraluminal lesions and further, incomplete resection of the lesion sometimes may lead to local recurrences. Nevertheless, presumably due to its latent growth, many years may be required for onset of the recurrence (24). In the present two cases, the lesion was so small and detected incidentally, implying that there was no urgent need for removal, but biopsy was necessary as a diagnostic procedure. Transbronchial biopsy contributed to an apparent removal of the lesions.

In conclusion, the diagnosis and selection of therapy are very complicated. In some cases with central lesions and peripheral lesions, diagnosis by biopsy is sometimes difficult due to the inappropriate amount of specimens collected, finally requiring a surgical diagnosis. In emergent cases presenting with tracheal obstruction, surgery must be chosen. The most challenging situation is provided by an asymptomatic endobronchial lesion which is definitively diagnosed as a neurilemmoma. Surgery is indispensable to resect the lesion completely. In the meantime, a bronchofiberoptic removal or an yttrium aluminum garnet (YAG) laser can be chosen as a palliative therapy; however, there is a possibility of local recurrence over a long interval. As a consequence, it is conceivable that bronchofiberoptic removal or a laser should be applied to younger patients as the first line therapy and if a local recurrence occurs, surgery should be chosen. For aged patients or patients with severe underlying diseases or malignancies, a bronchofiberoptic removal should be employed. To our knowledge, a local recurrence accompanied 


\section{KASAHARA et al}

with malignant changes has not yet been reported, indicating that concerns about such a recurrence can be circumvented.

\section{References}

1) Feldhaus RJ, Anene C, Bogard P. A rare endobronchial neurilemmoma (Schwannoma). Chest 95: 461-462, 1989.

2) Horovitz AG, Khalil KG, Verani RR, Guthrie AM, Cowan DF. Primary intratracheal neurilemmoma (Brief communications). J Thorac Cardiovasc Surg 85: 313-317, 1983.

3) Gouin B, Holler A, Segal J, Lavasseur P. Schwannoma de la trachee. Poumon Coeur 33: 189-193, 1977 (in French).

4) Kittinger G. Neurinom der Trachea. Mschr Ohrenheilk 95: 87-89, 1961.

5) Hiraoka T, Matsuura K, Shimizu M, Myojin K, Nakabayashi T, Hashimoto M. A case of tracheal neurinoma. J Jpn Assn Thorac Surg 38: 904, 1990 (in Japanese).

6) Ikezoe J, Sone $\mathrm{S}$, Higashihara $\mathrm{T}$, et al. Schwannoma of the trachea. Eur J Radiol 6: 65-66,1986.

7) Ishikawa $H$, Naito $T$, Ohtsuka M. A case of endobronchial neurilemmoma treated by transbronchofiberscopic resection. J Jpn Soc Bronchol 21: 300-303, 1999 (in Japanese with English Abstract).

8) Kase M, Sato H, Toyama I. A case of tracheal neurilemoma. Jpn J Thorac Surg 52: 336-339, 1999 (in Japanese with English Abstract).

9) Kawamura T, Murakami Y, Takebayashi T, et al. A case of pulmonary neurinoma with surgical resection. Jpn Assn Chest Surg 12: 381, 1998 (in Japanese).

10) Masui $T$, Yoshii $C$, Yatera $K$, et al. A case of bronchial neurinoma detected by bronchoscopy. J Jpn Soc Bronchol 22: 525-528, 2000 (in Japanese with English Abstract).
11) Nakamura H, Taniguchi $\mathrm{Y}$, Ito $\mathrm{N}$, et al. A case of pulmonary neurinoma associated with vagal nerve resected by thoracoscopy. Jpn Assn Chest Surg 10: 317, 1996 (in Japanese).

12) Niitsuma M, Nakamura $H$, Oho K. Tumors in trachea. Geka Shinryo 89: 1341-1348, 1986 (in Japanese).

13) Ohki K, Shibata I, Yamamoto Y, Makimoto K, Takahashi H. A case of tracheal neurinoma. J Jpn Bronchoesophagol Soc 42: 192, 1991 (in Japanese).

14) Shirakusa $T$, Takada $S$, Yamazaki $S$, et al. Intrabronchial neurilemmoma-Review of cases in Japan. Thorac Cardiovasc Surg 37: 388390, 1989.

15) Takamochi K, Sugimura H, Yokoyama Y, Neyatani H, Ohi S, Kobayashi R. A case of tracheal neurinoma with surgical resection. Jpn Assn Chest Surg 11: 426, 1997 (in Japanese).

16) Tsukada H, Osada H, Kojima K, Yamate N. A case of bronchial neurinoma resected by bronchoplastic operation. Jpn Assn Chest Surg 10: 317, 1996 (in Japanese).

17) Tsukioka T, Minobe M, Tunezuka N, Sato H, Kurumadani H. A case with successfully resected bronchial Schwannoma. Jpn J Chest Dis 58: 537-540, 1999 (in Japanese with English Abstract).

18) Uchiyama Y, Minami H, Yamashita M, Azuma K, Takahashi T, Nakamura A. A case of intrapulmonary Schwannoma. J Jpn Assn Thorac Surg 37: 1238-1241, 1989.

19) Yamaguchi $M$, Ohta $K$, Suzuki N, et al. Bilateral endobronchial Schwannoma detected by bronchoscopy. J Jpn Soc Bronchol 16: 391396, 1994 (in Japanese with English Abstract).

20) Yamakawa $T$, Nakahara $K$, Fujii $Y$, et al. Intrapulmonary Schwannoma; a case report. Jpn Assn Chest Surg 7: 165-171, 1993 (in Japanese with English Abstract). 